\title{
Antimicrobial Therapy of Experimental Human Leprosy (Myco. leprae) Infection in the Mouse Foot Pad
}

\author{
J. M. GAUGAS \\ Pharmacology Department, Guy's Hospital Medical School, London, S.E.1
}

Interest has arisen in recent years in a remarkably consistent method for the transmission of leprosy ( $M$. leprae) from man to mice which was first described by Shepard (1960, 1962). This finding was confirmed by other workers who used specimens of leprosy organisms obtained from patients in different countries (Rees, 1964; Pattyn and Janssens, 1965; Pattyn, 1965; Shepard and McRae, 1965). Unfortunately the lesion produced was always microscopic. Briefly, in a high proportion of mice challenged in their foot pads with between 10 and $10^{5}$ organisms, a mild form of infection was induced that developed very slowly and then regressed. In fact, multiplication only progressed to a limit of $10^{6}-10^{7}$ organisms for each foot and then stopped. However, inocula equal to this value (or even higher) did not undergo any increase.

The object of the present investigation was to examine the efficiency of the above technique as a routine method for determining antimicrobial activity. In order to undertake this fully a wide choice of compounds was used including a few of uncertain or unknown effectiveness against human infection.

MATERIALS AND METHODS

Source of $M$. leprae

The specimens of $M$. leprae used in the present investigation were obtained from 2 different sources and each contained a fairly high proportion of solid (viable) forms (Rees and
Valentine, 1962). Firstly, 3 specimens were extracted from biopsy material taken from untreated lepromatous patients in Malaya and these were supplied by the Medical Research Council through the courtesy of Dr. R. J. W. Rees (London, England). Secondly, 2 specimens were isolated from previously infected mice and these were kindly sent by Dr. C. C. Shepard (Atlanta, U.S.A.). All the specimens were dispatched (on ice at $0^{\circ} \mathrm{C}$ ) by air to London and were used for challenge within 3 days of removal from the host. Specimens of $M$. leprae bacteria were supplied in the form of a suspension, these failed to grow when seeded on to Lowenstein-Jensens medium even after 6 months incubation at $37^{\circ}$ or $32^{\circ} \mathrm{C}$.

\section{Animals}

Albino mice (mostly males) of about 6 weeks of age and derived from the I.C.I. pathogen free strain were used throughout.

\section{Inoculation}

The technique devised by Shepard was used to transfer leprosy to mice. Our own particular experimental methods for inoculation and subsequent harvesting of the organisms have been given in detail elsewhere (Gaugas, 1967). In order to induce infection each mouse was challenged in both its hind foot pads with an inoculum of $5.0 \times 10^{3}$ organisms. The fresh human biopsy isolates were used as the first or subsequent mouse transfers. 


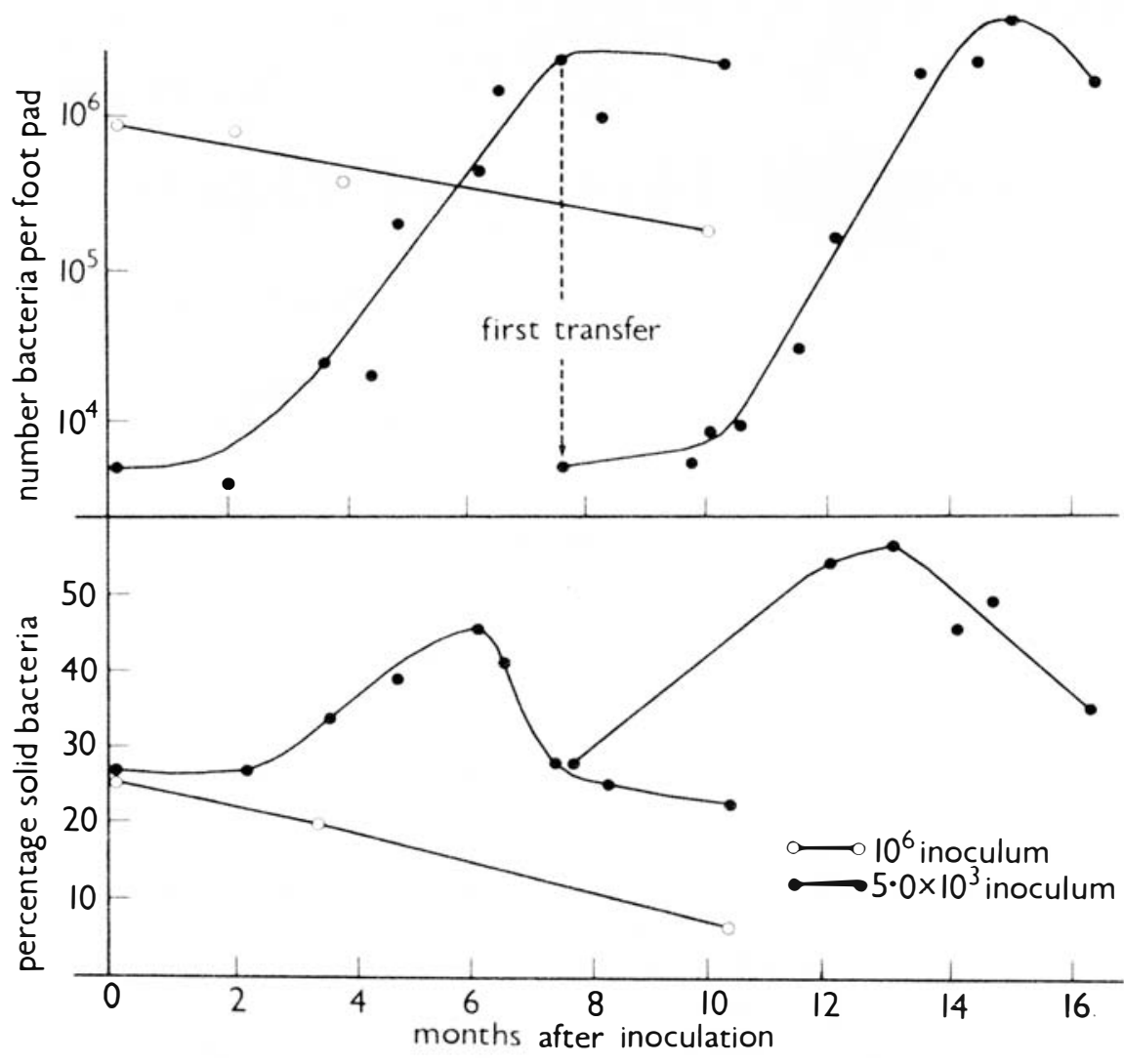

LEgEnd To Figure

Graph giving the growth curves (inoculum $5.0 \times 10^{3}$ bacteria) for the first and subsequent transfer of a fresh specimen of $M$. leprae in the mouse hind foot pad. No increase was obtained from an inoculum of $10^{6}$ bacteria. The total number of bacteria recovered as well as the corresponding percentage solid (i.e., viable) bacteria (ordinates) is plotted against time in months after inoculation (abscissa). Each point represents 1-6 foot pad estimations.

\section{Drug Treatment}

Administration of drugs was either by subcutaneous (s.c.) injection where each dose was usually dissolved in $0.2 \mathrm{ml}$. of sterile saline, or alternatively mixed in a powdered diet (i.e., orally). The regimen in the diet was based on a previous finding that mice ate $250 \mathrm{gm} . / \mathrm{kg}$. of food every day regardless of the amount offered. Treatment was generally given for 5-7 days a week and lasted until the maximal level of organisms was reached in the foot pads of untreated control mice after 7-9 months. At this juncture treated mice were killed and the foot pad content of organisms was estimated separately for each mouse. Groups of 12-30 surviving mice were used to determine the effectiveness of each course of treatment usually against a single specimen of $M$. le prae.

\section{RESULTS}

All the specimens of $M$. leprae behaved in a characteristic and predictable manner and this is illustrated (single example) by the growth curve in Fig 1. In order to obtain quantitative data on the infection it was necessary to continue checking the foot pad yield of organisms monthly. Here, from a convenient inoculum of $5.0 \times 10^{3}(26 \%$ solid $)$ organisms the limit of slightly above $10^{6}(24 \%$ solid $)$ was reached after about $7 \frac{1}{2}$ months. The infection, as expected, could be transferred from mouse to mouse. In contrast, a challenge dose of $10^{6}$ organisms failed to undergo multiplication.

The Table summarises the effect of various antimicrobial compounds (3 loosely defined classes) against this particular form of infection. It also enables a direct comparison to be made 
TABIE 1

Results of antimicrobial therapy of $M$. leprae in the mouse

Dose Effect Previous Investigation*

1. Anti-leprosy Drugs

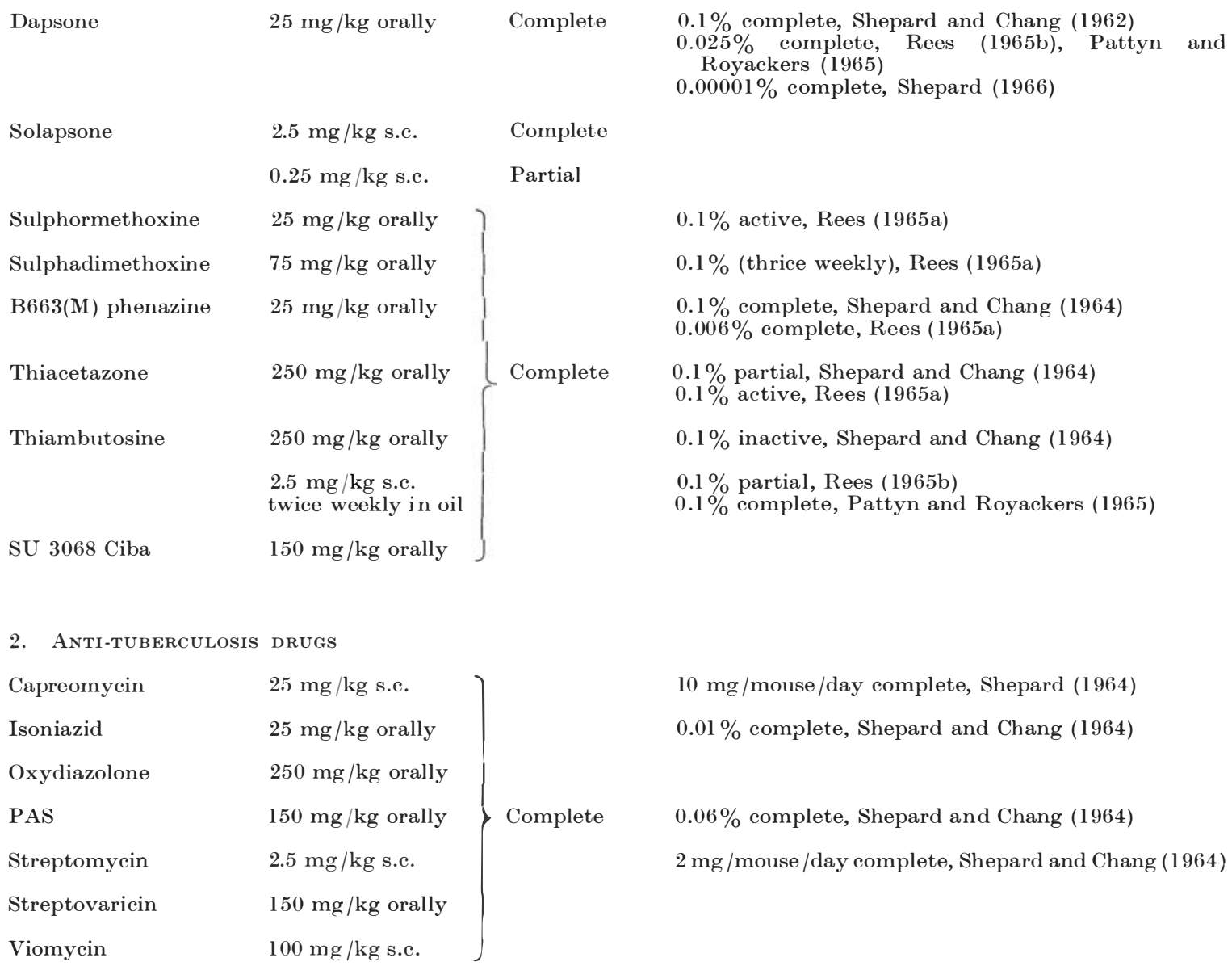

\section{BRoAd SPECTRUM ANTIMICROBials}

Cephaloridine

$300 \mathrm{mg} / \mathrm{kg}$ s.c.

Complete

Rifamycin

$150 \mathrm{mg}$ s.c.

Complete

Gentamicin

$165 \mathrm{mg} / \mathrm{kg}$ s.c.

Partial

Morphazinamide

$75 \mathrm{mg} / \mathrm{kg}$ orally

Ineffective

Tetracycline

$75 \mathrm{mg} / \mathrm{kg}$ s.c.

Ineffective

$75 \mathrm{mg} / \mathrm{kg}$ orally

Ineffective

\footnotetext{
* Generally expressed as percentage of drug in diet.
} 
with the results previously published by other workers who used the same screening technique. At first in our laboratory each compound was tested at its maximum tolerated dose (M.T.D.) for the mouse. Subsequently most of the compounds with a beneficial effect were tested with lower doses and only these later results are listed in the table. It can be seen that all the anti-leprosy drugs and all the anti-tuberculosis drugs we used prevented the multiplication of human leprosy organisms in the mouse. In addition, 2 broad spectrum antimicrobials cephaloridine and rifamycin also had the same effect. Previously thiambutosine was reported to be ineffective by Shepard and Chang (1964). However, this was not at first confirmed by Rees (1965a) but he later (1965b) observed irregular behaviour where some experiments resulted in complete inhibition and others resulted in partial or absence of activity. As he suggested, it is possible that this may be due to poor absorption in the mouse. In our own experiments complete inhibition was obtained for 2 specimens of $M$. leprae, one obtained from each of the above authors. In addition, subcutaneous administration (bi-weekly) of the drug suspended in arachis oil was also found to be effective. Due to the above discrepancy the thiazoline derivative of this compound, SU 3068 Ciba, was also tested since it is more soluble. Here also complete inhibition was observed.

It is noteworthy that the lower dose of solapsone prevented bacterial multiplication in just over half the number of animals treated. This was regarded as a partial effect. Hence the minimal effective dose (M.E.D.) must be slightly above this value of $0.25 \mathrm{mg}$. $/ \mathrm{kg}$. body weight. This result correlates reasonably well with that for a related compound, dapsone, recently found by Shepard, McRae and Habas (1966) to have a complete effect even at the very low concentration of $0.00001 \%$ in the diet. In fact, we found dapsone $(25 \mathrm{mg}$. $/ \mathrm{kg}$.) effective even if given only for the first $2 \frac{1}{2}$ months of the infection (although this result is not included in the Table). It is interesting that the human leprosy organism is very susceptible to sulphones. In this respect it is unlike any other pathogenic mycobacterium.

Information relevant to the pharmacology, toxicity and range of susceptible pathogens of the antimicrobials mentioned is readily available in the literature.

\section{DISCUSSION}

The mouse foot pad type of leprosy infection is easily cured from its inception by treating with a wide variety of antimicrobials, perhaps too easily in contrast to the disease in man. In human patients the problem is different since here infection, often with massive bacillary concentration, is already established before therapy begins. Moreover, the foot pad infection was too mild for assessing the value of combined drug therapy (if given for the duration of the infection). Nevertheless, the experimental infection does provide the only means readily available to date for the screening of potential anti-leprosy drugs other than in human subjects. This is because the organism responsible for leprosy in man cannot be grown on bacteriological media. One useful application of the mouse foot pad technique has already been demonstrated by Pettit and Rees (1964) and also by Adams and Waters (1966) where the occurrence of dapsone resistant $M$. leprae organisms from human patients (a total of 4 patients) was detected experimentally rather than by clinical observation. As a matter of interest the former patients then responded successfully to phenazine B 663 treatment (Pettit and Rees, 1966).

As a safeguard before starting trials with a new drug on human patients it would be desirable to determine the M.E.D. required to stop multiplication of leprosy organisms in the mouse foot pad, and then compare this result with that of related compounds (if any). When such a list has been finally compiled it is possible that a relative pattern of antimicrobial effect against leprosy infection may emerge approaching that already known for man. Owing to the long duration of the experiments and in the light of the experience gained it is recommended that extremely low doses of the compound should be given at the outset. Such a diversion 
from the routinely accepted method is probably due to the uniquely long generation time of about 26 days for $M$. leprae under these conditions, as well as the mildness of the infection in the mouse.

Finally in the future, attempts must be made to induce a more massive type of leprosy infection in experimental animals. At present, the key to inducing a more progressive leprosy disease appears to be by the use of powerful immunosuppressive treatment. Recently some success has been achieved along these lines by Rees $(1965,1966)$ and also by Gaugas (1967) where thymectomy plus $\mathrm{x}$-irradiation of adult mice markedly enhanced susceptibility to infection in the foot pad. Advantages are to be found in a more reliable way of testing the effectiveness of anti-leprosy drugs in so far as this may be more discriminating. It would also allow the usefulness of combined therapy to be evaluated in the experimental animal.

\section{SUMMARY}

In the present investigation Shepard's original method for transmission of human leprosy (M. leprae) to the mouse was confirmed. As expected a very mild form of infection was induced. This model was used to test the effectiveness of antimicrobial therapy. At largely arbitrary dose ranges treatment with dapsone, solapsone, sulphormethoxine, sulphadimethoxine, B663(M) phenazine, thiacetazone, thiambutosine, SU 3068, capreomycin, isoniazid, oxydiazolone, PAS, streptomycin, streptovaricin, viomycin, cephaloridine and rifamycin completely suppressed the development of the mild infection, but tetracycline or morphazinamide had no inhibitory effect; gentamicin had only a partial effect. The suitability of this method for the screening of compounds is discussed.

\section{ACKNOWLEDGEMENTS}

I should like to thank Professor J. M. Robson for his helpful advice, Miss P. Osborne for technical assistance, Dr. C. C. Shepard and Dr. R. J. W. Rees for supplying the leprosy materials, and the Medical Research Council for a grant which defrayed in part the cost of the present study.

The following Drug Houses kindly provided free gifts of antimicrobials: Bracco Chemical Industries S.p.A., British Schering Ltd., Burroughs Wellcome \& Co., Ciba Laboratories Ltd., Ed. Geistlich Sons Ltd., Eli Lilly \& Co. Ltd., Geigy Ltd., Glaxo Laboratories Ltd., Imperial Chemical Industries Ltd., Lepetit \& Co. Ltd., Parke, Davis \& Co., Roche Products Ltd., Smith \& Nephew Pharmaceuticals Ltd. and the Upjohn Co.

\section{REFERENCES}

Adams, A. R. D. and Waters, M. R. F. (1966). Dapsoneresistant lepromatous leprosy in England. Brit. Med. .J., 8, 872.

GAUGAS, J. M. (1967). Effect of x-irradiation and thymectomy on the development of Mycobacterium le prae infection in mice. Brit. J. exp. Path. In Press.

PATTYN, S. R. and JANSSENS, P. G. (1965). Experiences with mouse foot pad inoculation of leprosy bacilli originating from the Congo. Ann. Soc. Belge. Med. trop., 45, 1, 9-15.

PATTYN, s. R. and ROYACKERS, J. (1965). Traitement de l'infection experimentale a $M$. leprae chez la souris Ann. Soc. Belge. Med. trop., 45, 1, 27-30

PATTYN, S. R. (1965). Comparative behaviour of a strair of $M$. leprae in five different mouse strains and in thymectomised mice. Zbl. Bakt., Abt l Oriq., 197, $256-258$.

Pettit, J. H. S. and Rees, R. J. w. (1964). Sulphone resistance in leprosy Lancet (ii), 673-674.

PetTit, J. H. S. and ReEs, R. J. W. (1964). Sulphone resistance in leprosy. 2. Treatment with a riminophenazine derivative (B663). Int .J. Lepr., 34, 4, 391-397.

ReEs, R. J. W. and valentine, R. C. (1962). The appearance of dead leprosy bacilli by light and electron microscopy Int. .J. Lepr., 30, 1, 1-9.

REES, R. J. W. (1964). Limited multiplication of acid-fast bacilli in foot pads of mice inoculated with Mycobacterium leprae. Brit. J. exp. Path., 45, 207-218.

REES, R. J. w. (1965a). Recent bacteriologic, immunologic and pathologic studies on experimental human leprosy in the mouse foot pad. Reprinted from Proceedings LWM-AFIP Conf. Int. .J. Lepr., 33, 3, Pt. 2, 646-655.

REES, R. J. W. (1965b). Recent applications of experimental human leprosy in the mouse foot pad. Reprinted from July Supplement Issue (No. 3A) of Leprosy in India, 1-6.

REES, R. J. W. (1966). Enhanced susceptibility of thymectomized and irradiated mice to infection with Myco. leprae. Nature (Lond.), 211, 5049, 657. 
SHEPARD, C. C. (1960). The experimental disease that follows the injection of human leprosy bacilli into foot pads of mice. J. exp. Med., 112, 445-454.

SHEPARD, C. C. (1962). Multiplication of Mycobacterium leprae in the foot pad of the mouse. Int. J. Lepr., 30, 3, 291-306.

SHEPARD, C. C. and CHANG, Y. T. (1964). Activity of antituberculosis drugs against Mycobacterium leprae. Studies with experimental infection of mouse foot pads. Int. J. Lepr., 32, 3, 260-271.
SHEPARD, C. C. and CHANG, Y. T. (1962). Effect of several anti-leprosy drugs on multiplication of human leprosy bacilli in foot pads of mice. Proc. Soc. exp. Biol. Med., 109, 636-638.

SHEPARD, C. C. (1964). Capreomycin: activity against experimental infection with Mycobacterium leprae. Science N.Y., 146, 3642, 403-404.

SHEPARD, C. C., MCRAE, DOROTHY H. and habAs, JANET A. (1966). Sensitivity of Mycobacterium lepraf to low levels of 4,4'-diaminodiphenylsulphone. Proc. Soc. exp. Biol. Med., 122, 893-896. 